\title{
Grand Challenges and Chemical Engineering Curriculum - Developments at TU Dortmund University
}

\author{
Norbert Kockmann ", Philip Lutze, Andrzej Gorak \\ Department of Biochemical and Chemical Engineering, TU Dortmund University, Germany
}

Copyright (C) 2016 by authors, all rights reserved. Authors agree that this article remains permanently open access under the terms of the Creative Commons Attribution License 4.0 International License

\begin{abstract}
Chemical processing industry is progressively focusing their research activities and product placements in the areas of Grand Challenges (or Global Megatrends) such as mobility, energy, communication, or health care and food. Innovation in all these fields requires solving high complex problems, rapid product development as well as dealing with international competition. These factors should also be reflected in modern chemical and biochemical engineering curricula. At TU Dortmund University, chemical and biochemical engineering education has a long tradition in combining fundamental knowledge in natural science with engineering skills. Hence, the introductory course on chemical engineering already presents the subject in view of the aforementioned global challenges. Fundamentals in chemical engineering incorporating and related subjects, problem-based learning as well as design skills and problem-solving techniques are trained throughout later courses. Lectures, tutorials, and practical work are accompanied by a plant design project, placed at the end of the Bachelor curriculum. Here a group of 8 to 10 students develop a complete production plant. Students are often directly involved with research projects during the last phase of their education, i.e. Bachelor or Master thesis. With the final presentation and "defence" of their work, the students are well prepared for their industrial experience.
\end{abstract}

Keywords Global Challenges, Chemical Engineering Curriculum, Plant Design Project, Problem-based Learning, Research-oriented Learning

\section{Introduction}

In chemical industry many challenges, but opportunities for new products, too, are directly linked with current global needs [1]. Demographic change, higher living standards, reliable and healthy food supply, environmental challenges and burdens dominate already today's company's product profile and development. Their investment strategies follow growing markets leading to technical and intercultural challenges [2].

Chemical Engineering is one of the key disciplines, shaping our world for better living [3]. To educate engineers, who understand those needs, Biochemical and Chemical Engineering Faculty (BCI) at TU Dortmund University developed curricula, consisting of teaching in engineering and natural sciences together with mathematics and economics. From scientific point of view, we teach students in chemistry and chemical engineering basics. Modern chemical engineers are team players; hence, students have to learn interacting with different professions. We educate engineers, who have an understanding of the Grand Challenges or Megatrends of our world from the early start of their studies [4],[5]. The Bachelor program provides an interdisciplinary study, enabling an understanding of new concepts and innovations for developing, optimizing, and operating complex production processes and equipment. The Master program has more elective courses and leads the graduate students to more self-conscious and science-oriented learning. It is our concept to bring students in contact with industry in the early stage of their curriculum. We promote female students and we have worked out sophisticated teaching concepts for all phases of the study.

\section{From History of BCI Faculty}

In 1969 the Department „Chemical Engineering“ was founded as one of the first faculties of the former University of Dortmund, today TU Dortmund University (Fig. 1). Starting with a small number of staff members and labs only the first years saw a tremendous growth with rapidly increasing numbers of professors, lab space as well as students. Half of the academic staff was recruited from industry shaping the project-oriented curriculum. Irrespective of all starting challenges the first students graduated five years later. 


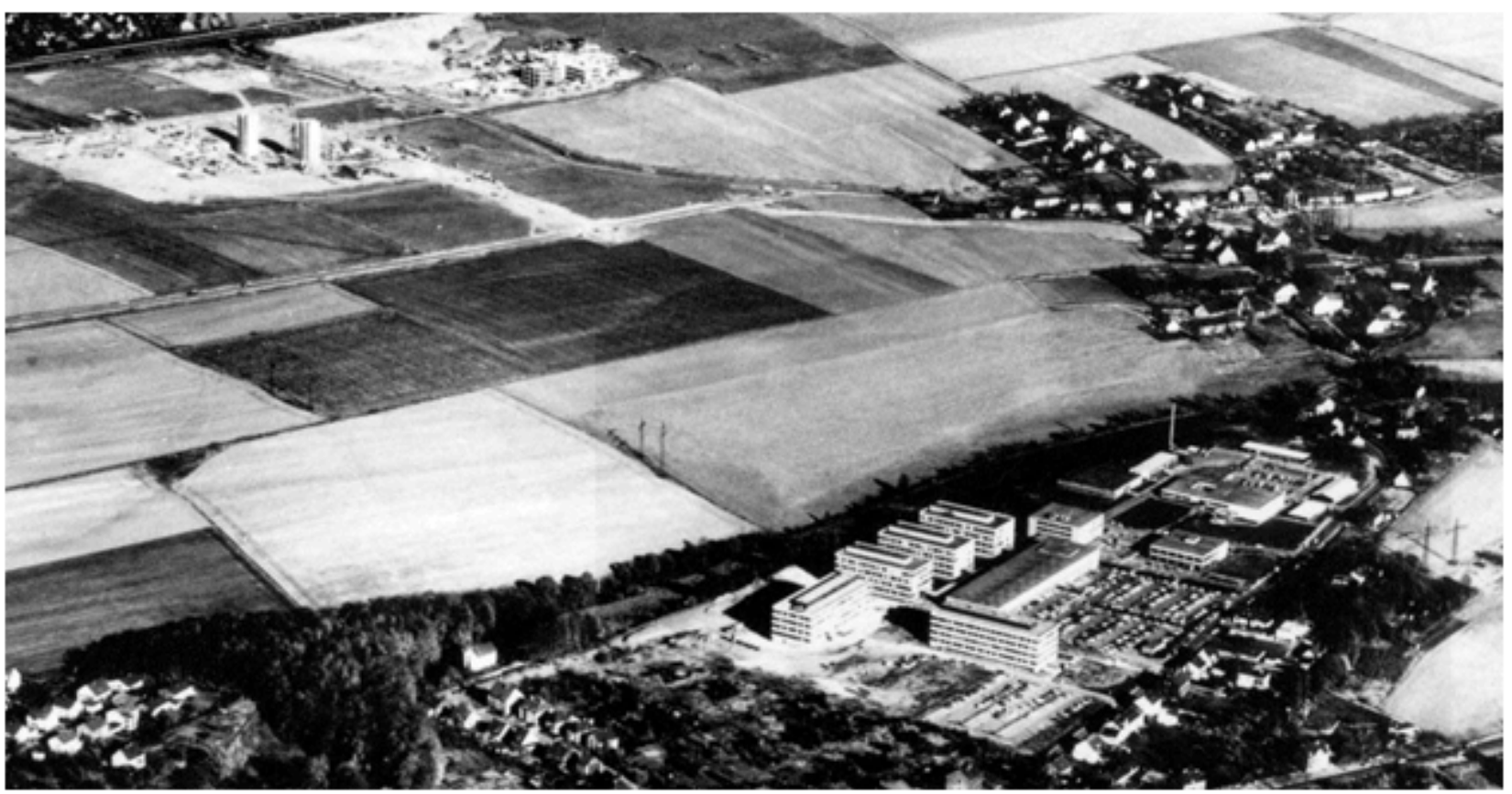

Figure 1. Campus from 1971 showing the first nucleus in the front with modern tall buildings and the construction site of the North Campus with buildings for Chemical Technology in the upper left corner [6].

The department takes a particular pride in its high number of female students of approximately $35 \%$ on average, and in 2001 the faculty happily welcomed Gabriele Sadowski as first female professor. Moreover, the department is also a truly international one: To open it to students from abroad and implement modern BSc (7 semesters) and MSc (3 semesters) curricula English language programs and courses were introduced. More than 170 students graduated in this teaching programme of Process Systems Engineering with only courses in English.

As biochemical processes play an increasingly important role in chemical engineering nowadays, the Faculty has changed in 2003 his name to "Biochemical and Chemical Engineering". This was a consequence of restructuring the old diploma degree program to the new Bachelor and Master system in Chemical Engineering (Bologna reform) and introduction of a Biochemical Engineering as new degree program. In the following years we extended and re-structured our research and teaching in Biochemical Engineering. Today, we are the biggest departments of its kind in Europe.

\section{Starting into Chemical and Biochemical Engineering Studies}

The study of Chemical Engineering comprises courses in a broad variety of fields, starting with basic courses in mathematics and chemical and physical sciences, as well as engineering leading afterwards to courses in technical chemistry, reaction technology, engineering fundamentals, modelling as well as equipment and plant design [7],[8].

Biochemical Engineering is a new discipline at the interface between natural sciences and engineering arts. The undergraduate program in Biochemical Engineering contains a set of core knowledge of Chemical Engineering together with courses in molecular and cellular biology, biochemistry, biotechnology, microbiology, as well as engineering analysis of systems level biology and physiology.

To motivate the freshmen from the beginning and to illustrate the opportunities in later professional environment, a general Introductory Course on the respective disciplines was installed from the beginning in both Bachelor curricula [9],[10]. The teaching courses embrace first insights into chemical industry, mass balances, transport processes, reaction kinetics and reactors, separation units and plant design with cost calculation. Within the second part of this module, groups with 4 to 5 students work in a team supervised by a PhD student on a topic oriented at the grand challenges to produce a short report and a poster presentation (Fig. 2). Apart from applying the newly achieved knowledge and create own results, students find mutual contact for later learning groups or other activities. They are proud to discuss their results with an interested audience of students, researches and academia.

Both Bachelor programs in Biochemical and Chemical Engineering provide an interdisciplinary study to comprehend new concepts and innovations for developing, optimizing and operating complex production processes based in modern chemical or biotechnological principles. 

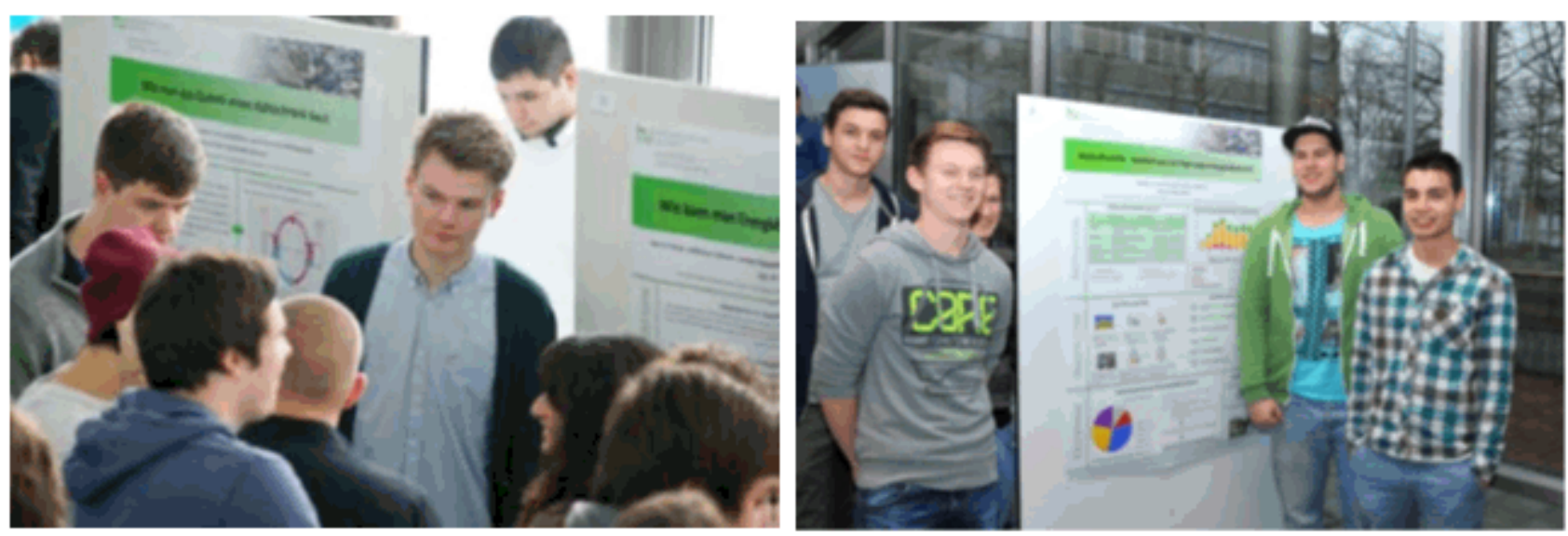

Figure 2. Poster presentation with nearly 40 groups resulting from the introductory course

The Bachelor program for both directions comprises 7 semesters study, including a plant design project, an industrial internship and Bachelor thesis as final project qualifying for direct access to industry or continuation in his Master study. Our sophisticated Bachelor program provides students all necessary knowledge and skills to work as an engineer in the biochemical or in the chemical industry and related sectors like pharma, food or energy (Tab. 1). The students acquire a broad knowledge in chemistry and biotechnology, mechanical and process engineering, as well as process safety understanding. Also courses in Business Economics and Technical English are included.

Table 1. Overview of main curriculum content of Chemical and Biochemical engineering studies

\begin{tabular}{|c|c|}
\hline Chemical Engineering & Biochemical Engineering \\
\hline \multicolumn{2}{|c|}{ Natural Sciences, Mathematics, Business Economics } \\
\hline Process and Plant Design & Genetics \\
\hline Chemical Process Engineering & Biochemistry \\
\hline Process Systems Engineering & Bioengineering \\
\hline Product Design & Biotechnological Research \\
\hline
\end{tabular}

The Biochemical Engineering program at our faculty is a unique and interdisciplinary program in Germany combining engineering and natural sciences. Biochemical Engineering is the merger of engineering with biological sciences in the study of complex living systems (microorganisms, plants, animals). Bioengineering research at TU Dortmund University focuses on the development of innovative or improved biological and biotechnological concepts and techniques that can be applied to problems in industrial biotechnology, pharmaceutical and related sciences. This includes the fundamental study of biological phenomena and the development of bio-based processes in all areas of biotech industries.

\section{Problem-based Learning}

Apart from the Introductory Course and group work with poster presentation, some topics in the curriculum are conveyed by problem-based learning. Reaction Engineering contains specific assignments, while programming courses are taught on practical examples. Design thinking is an important part and is trained in Process and Plant Engineering as well as in Equipment Technology \& Design.

The last course in both Bachelor curricula is on Equipment Technology \& Design introducing pressure vessel code and design, piping, construction materials, heat exchangers and columns. As core competence, a design methodology based on Six Sigma [11] with the method IDOV (Identify - Design - Optimize - Validate, Fig. 3) is taught to create novel solutions for complex tasks. The students have to analyse a problem description, identify conflicts in the task description, develop solutions strategies, and sketch design concepts [12]. In the exam the students have to work on typical technical tasks such as corrosion, fouling, vessel improvements or revamps. E.g. the students should develop and sketch different solution possibilities to prevent valve blockage in particulate pipe flow. They learn the way from knowledge to creativity and are trained on this knowledge-based creativity for later complex applications.

Both curricula comprise an industrial internship of 9 weeks minimum and a Plant Design Project (Gruppenarbeit in German), in which a team of 8 to 10 students work on a basic engineering design for an entire production plant within 8 weeks. In weekly presentations with intense discussion, the students start to identify themselves with the project and dwell deep into typical engineering tasks. The group is self-organized and goes stepwise through all planning phases starting from conceptual process design including reaction kinetics and separation units' identification to detailed engineering (plant layout) up to cost calculation. The students present their results during public dispute in the Faculty and also in the company, which operates a process similar to the one, which was designed by student group. It gives the students the experience of working as "real engineer". This experience in the context of a practical example pulls together many of the knowledge the students have learnt earlier in the different disciplines. In the seventh semester the study is completed by the Bachelor thesis. With the Bachelor degree the graduates are able to work as engineers in all kinds of chemical companies or to continue Master's study. 


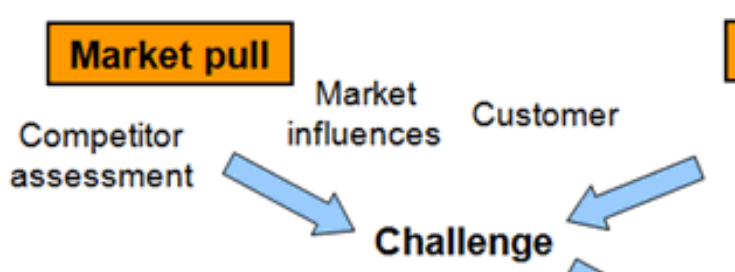

\section{Technology push}

Fabrication and technological capabilities, material development

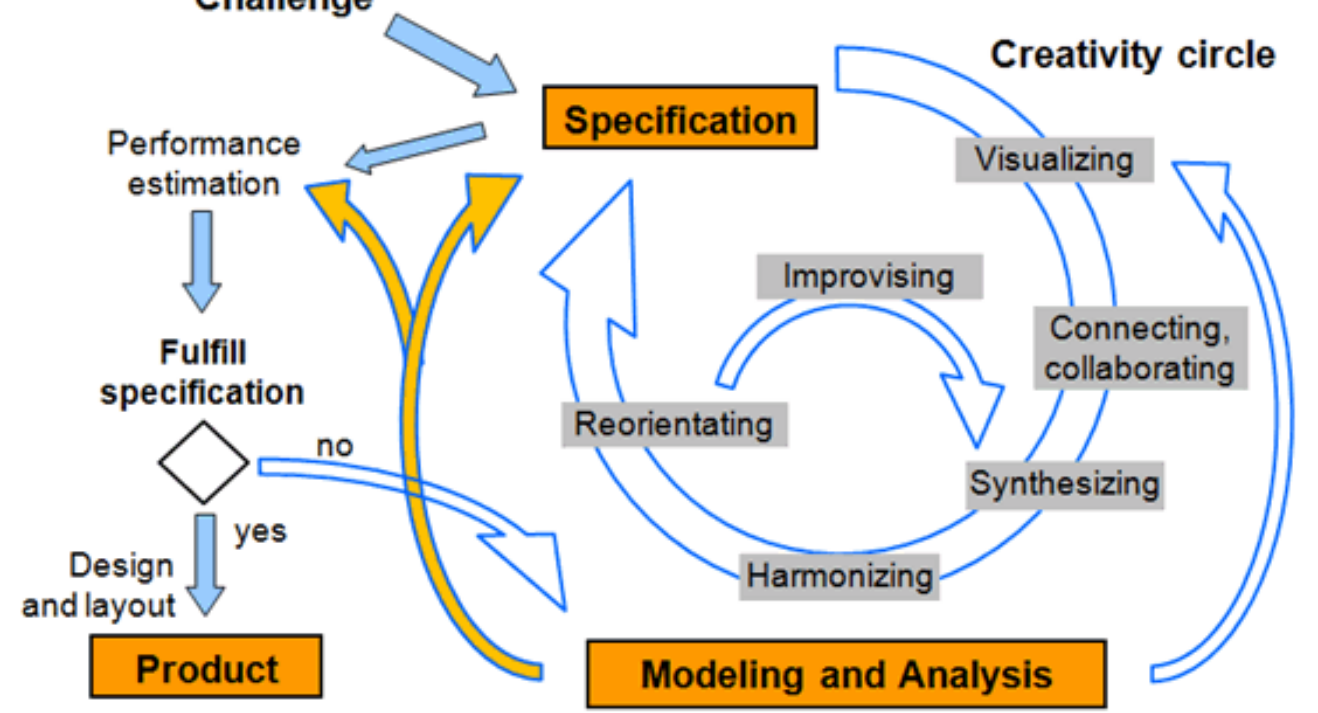

Figure 3. Creativity circle as part of the Equipment Technology \& Design course, which reflects also the Global Challenges of chemical industry

\section{Research-oriented Learning}

The Master program in Chemical Engineering focusses on research and opens the door for first scientific activities. In three semesters the student has a wide choice in different elective courses concerning for instance Advanced Reactor Technology and Advanced Separations, Process Dynamics and Control, Particle Technology and Product Design, Technical Catalysis, or Polymer Thermodynamics. This study comprises a full semester Master's thesis, which is carried out on own choice in one of the faculty's laboratories (Fig. 4). The Master graduate in chemical engineering is a highly qualified expert, who may take over a leading position in chemical industry or continues her studies as a $\mathrm{PhD}$ in one of the research groups of the faculty.

Additionally, an English Master's Degree on Process Systems Engineering teaches internationally oriented students the basics of scientific process engineering. The program comprises further 3 semesters, including a full semester Master thesis. It receives between 20 and 40 students from foreign national and international universities and applied science faculties showing the attractiveness of our studies. A pre-semester with fundamental process engineering courses is offered to students with less precognition. The specialization in Process Systems Engineering emphasizes on Modelling and Computer Simulation, Process Optimization, Dynamics and Control, as well as Conceptual Process Design.

The Biochemical Engineering Master's degree requires successful completion of teaching modules comprised of a mixture of Molecular Biotechnology, Analytics,
Pharmaceutical Engineering, Process Design, Process Performance Engineering and elective classes as well as successful completion of a Master thesis. We offer students to work on their Master thesis also in labs of accredited partner universities. With their degree in Biochemical Engineering Masters the students have acquired a well-founded scientific knowledge and appropriated and state-of-the-art methods for a multitude of various engineering tasks.

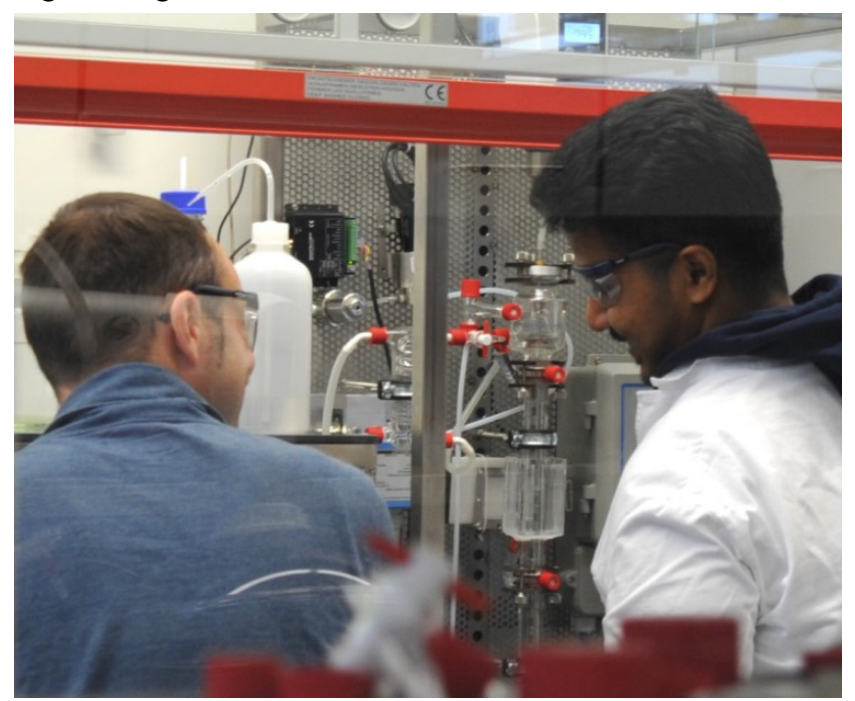

Figure 4. Graduate students in the laboratory working on a miniaturized stirred column for extraction experiments

All graduates are well prepared for highly qualified work and leading positions in industry and often continue with $\mathrm{PhD}$ studies. 


\section{Conclusions}

The leitmotif in educating young engineers is to develop and optimize safe, sustainable, and efficient production processes. Our teaching concept relies on a strong interaction of natural and engineering sciences. We identified three focal points for the education (and research as well) of the department as a whole: Chemical Process Engineering, Sustainable Biochemical Engineering, and Product Development and Process Engineering for the wide range of chemical and biochemical processes and products.

The distinguishing feature of our educational approach is the integrated view of the whole process, from the chemical reaction to the separation steps and recycles, leading to efficient and environmentally benign processes. This way of thinking is taught to the students in various courses from the Introductory Course to Equipment Technology \& Design as well as in the Plant Design Project with high industrial relevance and in the Bachelor thesis. The Master's curricula guide the student to research-oriented working in elective courses and their final Master thesis, often part of research projects at the faculty. With these blended learning methods the various demands of later engineering and research tasks are conveyed to young engineers to prepare them well for their later professional environment. This is documented by high success rates of our alumni and good acceptance of industry and academia.

\section{Acknowledgements}

The authors want to thank Dr.-Ing. Paul Kerzel, and Mrs. Kirsten Lindner-Schwentick for providing data and information on the current development of our faculty.

\section{REFERENCES}

[1] Manley, J. B., Anastas, P. T., Cue, B. W. (2008). Frontiers in Green Chemistry: meeting the grand challenges for sustainability in R\&D and manufacturing. Journal of Cleaner Production, 16(6), 743-750.

[2] Reubold, M. (2012). Megatrends als Wachstumstreiber, Mit Premiumprodukten für globale Wachstumsmärkte will Lanxess seine Erfolgsgeschichte weiterschreiben, CheManager 20. 2012

[3] Westmoreland, P. R. (2014). Opportunities and challenges for a Golden Age of chemical engineering. Frontiers of Chemical Science and Engineering, 8(1), 1-7.

[4] Grand Challenges for Engineering. Washington, DC: National Academies Press; 2008.

[5] Tuerk, A. L., Lee, K. H. (2014). The evolving engineer. AIChE Journal, 60(6), 1956-1963.

[6] www.bci.tu-dortmund.de/de/fakultaet/allgemeines/chronik, accessed Dec 11, 2015

[7] Allen, D. T., Shonnard, D. R. (2012). Sustainability in chemical engineering education: Identifying a core body of knowledge. AIChE Journal, 58(8), 2296-2302.

[8] Braun, B., Charney, R., Clarens, A., Farrugia, J., Kitchens, C., Lisowski, C., Naistat, D., O'Neil, A. (2006). Completing our education. Journal of chemical education, 83(8), 1126-1129.

[9] Whitfield, C. A., Freuler, R. J., Allam, Y., Riter, E. A. (2011, August). An overview of highly successful first-year engineering cornerstone design projects. In Proceedings of the 2011 International Conference on Engineering Education.

[10] Dutson, A. J., Todd, R. H., Magleby, S. P., Sorensen, C. D. (1997). A Review of Literature on Teaching Engineering Design Through Project - Oriented Capstone Courses. Journal of Engineering Education, 86(1), 17-28.

[11] Yang, K., El-Haik, B. (2003). Design for Six Sigma - A Roadmap for Product Development, McGraw-Hill, New York

[12] Doggett, A.M. (2005). Root Cause Analysis: A Framework for Tool Selection, Qual. Mngmt. J., 12(4), 34-45. 